\title{
O MEIO AMBIENTE CULTURAL E SUA REPERCUSSÃO NO PROCESSO TERAPÊUTICO DOS TRANSTORNOS MENTAIS
}

\author{
Tássia dos Anjos Andrade* \\ Laila Soares Cavalcante ${ }^{* *}$
}

\begin{abstract}
RESUMO: O presente artigo tem por objetivo demonstrar a influência que o meio ambiente cultural exerce no processo terapêutico inerente aos transtornos mentais. Para tanto, apresenta uma abordagem histórica acerca da introdução de práticas culturais no processo curativo dos problemas relacionados à saúde mental e analisa os possíveis efeitos gerados no indivíduo e no seio social. A pesquisa utilizou-se da metodologia dedutiva para demonstrar os benefícios que a adoção de manifestações culturais acarreta no processo curativo dos transtornos mentais, de modo a ampliar a sociabilidade do paciente e auxiliar o tratamento.
\end{abstract}

Palavras-chave: Meio ambiente cultural; saúde mental; práticas culturais; tratamento alternativo; benefícios advindos.

\section{THE CULTURAL ENVIRONMENT AND ITS REPERCUSSION IN THE THERAPEUTIC PROCESS OF MENTAL DISORDERS}

\begin{abstract}
This article aims to demonstrate the influence that the cultural exerts on the therapeutic process inherent in mental disorders. To do so, it presents a historical approach to the introduction of cultural practices in the curative process of mental health problems and analyzes the possible effects generated in the individual and in the social environment. The deductive methodology was used to demonstrate the benefits that the adoption of cultural manifestations entails in the curative process of the mental disorders, in order to increase the sociability of the patient and to aid the treatment.
\end{abstract}

Keywords: Cultural environment; mental health; cultural practices; alternative treatment; benefits.

\section{INTRODUÇÃO}

O meio ambiente cultural, formado pelo conjunto de bens materiais e imateriais que compõem o chamado patrimônio cultural de um povo, possui considerável abrangência.

\footnotetext{
*Mestranda em Direito da Saúde pela Universidade Santa Cecília. Pós-Graduada em Direito Público pela Faculdade Baiana de Direito em parceria com JUSPODIVM. Graduada em Direito pela Universidade Católica do Salvador. Procuradora do Município de Maceió. E-mail: tassiaanjos@hotmail.com. Endereço postal: Rua Bancário José Farias de Almeida, n. 166, ap. 505, Jatiúca. CEP: 57036-440, Maceió/AL.

${ }^{* *}$ Mestranda em Direito à Saúde pela Universidade Santa Cecília. Pós-graduada em Direito Público pela UNIDERP. Graduada em Direito pelo Centro Universitário CESMAC. Procuradora do Município de Maceió. Email: lailasoarescavalcante@gmail.com. Endereço postal: Rua Coronel Alcides de Barros, n. 206, ap. 201, Jatiúca. CEP: 57036-480, Maceió/AL.
} 
Incluem-se, dentre esses bens, os de natureza artística, paisagística, arqueológica, histórica e turística, sendo responsáveis por conferir referências de identidade, costumes, memória e cidadania aos grupos formadores de uma dada sociedade.

Ao lado do meio ambiente natural, possui notável relevância para a preservação da sadia qualidade de vida dos indivíduos, especialmente em razão do valor diferenciado que representa para a sociedade e seu povo (MIRANDA, 2006, p. 179). Assim, o acervo patrimonial que integra a cultura de um país denota importância salutar para o bem-estar do indivíduo e para a representação de sua própria identidade, tendo papel de relevo na dignidade humana, razão pela qual merece proteção em similar medida. Não bastasse tudo isso, possui natureza de bem difuso, pertencente a toda coletividade.

No caso brasileiro, a Constituição Federal, no art. 216, prevê, de forma expressa, serem patrimônio cultural do país “os modos de criar, fazer e viver”, "as formas de expressão”, “as obras e espaços destinados às manifestações artístico-culturais” e as demais manifestações culturais que conferem identidade ao povo (BRASIL, 1988). Nesse cenário, inserem-se, portanto, atividades musicais, pintura, artesanato, atividades folclóricas, manifestações decorrentes de cultura regional, cinema e uma gama, quase infindável, de atividades artísticas e culturais que materializam a cultura brasileira.

Questiona-se, porém, se essa inegável importância do patrimônio cultural sobre a vida dos cidadãos também encontra reflexos quando utilizado como uma ferramenta de tratamento em benefício dos portadores de transtornos mentais, sobretudo após o movimento de desistitucionalização promovido pela reforma psiquiátrica ocorrida no país na década de 1970 e os estudos realizados a partir de então.

Na presente abordagem, será utilizada a metodologia dedutiva para demonstrar os possíveis benefícios que a adoção de manifestações culturais pode acarretar no processo curativo dos transtornos mentais, especialmente através da ampliação da sociabilidade do paciente e possíveis benefícios daí advindos.

Nesse estudo, analisaremos, portanto, aspectos como o desenvolvimento de maior sociabilidade do paciente, estímulo à criatividade, melhora da autoestima e diminuição da exclusão social, quando utilizadas práticas decorrentes de manifestações culturais no processo terapêutico. Analisaremos, ainda, o contexto histórico que culminou na adoção dessas atividades, bem como se a promoção das variadas formas de manifestações culturais aos portadores de transtornos mentais é capaz de ultrapassar o benefício auferido pelo próprio 
paciente e implicar em transformação social, a partir de uma eventual redução da exclusão e do estigma que com si carregam.

Diante disso, compreendemos que o estudo proposto é de grande relevância jurídica e social, pois trata de tema extremamente sensível à população e busca demonstrar uma relação equitativa entre preservação do meio ambiente e promoção da saúde, constituindo - ambos direitos sobremaneira relevantes.

\section{MEIO AMBIENTE CULTURAL: ASPECTOS CONCEITUAIS}

A Constituição Federal, em seu art. 225, define que o meio ambiente ecologicamente equilibrado constitui direito fundamental constitucional, de natureza eminentemente difusa, e denota a qualidade de bem indispensável à sadia qualidade de vida dos indivíduos (BRASIL, 1988). Conquanto muito se refira ao seu aspecto natural ou biológico, é cediço que o meio ambiente, globalmente considerado, comporta outras esferas - compreendidas suas dimensões cultural, artificial e do trabalho (CARDOSO, 2011, p. 22) - que, em breve síntese, podem assim ser definidas:

Meio ambiente natural ou físico é aquele formado por elementos integrantes da natureza, como a água, o solo, o ar atmosférico, a flora e a fauna, além de todos os demais elementos naturais responsáveis pelo equilíbrio dinâmico entre os seres vivos. Meio ambiente cultural é composto pelo patrimônio histórico, artístico, arqueológico, paisagístico, turístico e científico. Meio ambiente artificial, por sua vez, é o constituído pelo conjunto de edificações, equipamentos públicos, ruas, praças, rodovias e demais elementos que formam o espaço urbano construído. (ALVARENGA, 2014, p. 01)

[O meio ambiente do trabalho constitui] “o conjunto (=sistema) de condições, leis, influências e interações de ordem física, química, biológica e psicológica que incidem sobre o homem em sua atividade laboral, esteja ou não submetido ao poder hierárquico de outrem”. (FELICIANO, 2013, p. 13)

Esses quatro aspectos não devem ser, todavia, analisados isoladamente, mas em conjunto, sem que estabeleçam compreensões estanques entre eles. Como bem lembra ANTUNES (2009, p. 09):

Meio ambiente compreende o humano como parte de um conjunto das relações econômicas, sociais e políticas que se constroem a partir da apropriação dos bens naturais que, por serem submetidos à influência humana, transformam-se em recursos essenciais para a vida humana em quaisquer de seus aspectos. 
No que atine especificamente ao patrimônio cultural brasileiro, é imperioso lembrar que tem previsão constitucional e abrange bens materiais e imateriais, superando a antiga previsão contida no Decreto-lei n. 25/1937¹ (BRASIL, 1937), que incluía em sua definição apenas os bens materiais ou tangíveis. O art. 216 da Constituição Federal (BRASIL, 1988) demonstra a amplitude desse complexo de bens ao discriminá-los, em rol não exaustivo, da seguinte forma:

Art. 216. Constituem patrimônio cultural brasileiro os bens de natureza
material e imaterial, tomados individualmente ou em conjunto, portadores de
referência à identidade, à ação, à memória dos diferentes grupos formadores
da sociedade brasileira, nos quais se incluem:
I - as formas de expressão;
II - os modos de criar, fazer e viver;
III - as criações científicas, artísticas e tecnológicas;
IV - as obras, objetos, documentos, edificações e demais espaços destinados
às manifestações artístico-culturais;
V - os conjuntos urbanos e sítios de valor histórico, paisagístico, artístico,
arqueológico, paleontológico, ecológico e científico.
§ $1^{\circ}$ O Poder Público, com a colaboração da comunidade, promoverá e
protegerá o patrimônio cultural brasileiro, por meio de inventários, registros,
vigilância, tombamento e desapropriação, e de outras formas de
acautelamento e preservação. (BRASIL, 1988)

Os bens integrantes do patrimônio cultural brasileiro conferem, pois, referência e identidade a toda a nação, contribuindo, assim, para a construção dos valores consagrados na sociedade. Abrange os bens materiais, como obras, objetos, documentos, edificações e demais espaços destinados às manifestações artístico-culturais, conjuntos urbanos e sítios de valor histórico, paisagístico, artístico, arqueológico, paleontológico, ecológico e cientifico; além de bens imateriais, como as formas de expressão, modos de criar, fazer e viver, criações científicas, artísticas e tecnológicas e toda forma de expressão cultural da nação brasileira.

Sobre o tema, esclarecedoras são as palavras de MIRANDA (2006, p. 180):

O conceito hodierno de meio ambiente não se resume ao seu aspecto meramente naturalístico, mas comporta uma conotação abrangente, holística, que engloba inclusive os bens de valor histórico e artístico, sendo necessário que os operadores do direito se atentem para este fato, pois somente assim será possível alcançar a proteção integral do meio ambiente, assegurando que os bens de valor cultural, que também são essenciais à sadia qualidade de vida de todos nós, possam ser usufruídos pelas presentes e pelas futuras gerações.

\footnotetext{
${ }^{1}$ Art. $1^{\circ}$ Constitue o patrimônio histórico e artístico nacional o conjunto dos bens móveis e imóveis existentes no país e cuja conservação seja de interêsse público, quer por sua vinculação a fatos memoráveis da história do Brasil, quer por seu excepcional valor arqueológico ou etnográfico, bibliográfico ou artístico. (BRASIL, 1937)
} 
Dessa forma, podemos perceber que o meio ambiente equilibrado, considerado em sua globalidade e nele incluído, portanto, o meio ambiente cultural, como o próprio texto constitucional indica, é voltado para a satisfação das necessidades humanas.

O equilíbrio do meio ambiente, requer, pois, o equilíbrio simultâneo das quatro esferas que o compõem. Em vista de sua conotação multifacetária, a tutela jurídica da esfera cultural, em pé de igualdade com as demais, se mostra necessária para que se possa garantir a sadia qualidade de vida delineada na Constituição Federal.

E, nesse sentir, determina o seu artigo 215:

Art. 215. O Estado garantirá a todos o pleno exercício dos direitos culturais e acesso às fontes da cultura nacional, e apoiará e incentivará a valorização e a difusão das manifestações culturais.

$\S 1^{\circ} \mathrm{O}$ Estado protegerá as manifestações das culturas populares, indígenas e afro-brasileiras, e das de outros grupos participantes do processo civilizatório nacional. (BRASIL, 1988)

Nesse aspecto, nota-se, a partir do texto constitucional, ser papel do Estado proporcionar o acesso à cultura, garantir o seu exercício e incentivar a produção e difusão das manifestações culturais. Com vistas a materializar o exercício desses direitos, a EC n. 48/2005 (BRASIL, 2005) inseriu o parágrafo $3^{\circ}$ no supracitado art. 215 para prever a criação de um Plano Nacional de Cultura "visando ao desenvolvimento cultural do País e à integração das ações do poder público que conduzem à”:

I - defesa e valorização do patrimônio cultural brasileiro;

II-produção, promoção e difusão de bens culturais;

III-formação de pessoal qualificado para a gestão da cultura em suas múltiplas dimensões;

IV- democratização do acesso aos bens de cultura;

V-valorização da diversidade étnica e regional. (BRASIL, 1988)

Esse plano veio a ser instituído pela Lei $\mathrm{n}^{\circ}$. 12.343/2010 (BRASIL, 2010), com princípios (art. $1^{\circ}$ ) e objetivos (art. $2^{\circ}$ ) expressamente delineados, dentre os quais, neste último caso, destacamos: o reconhecimento e a valorização da diversidade cultural, étnica e regional brasileira (inc. I); a proteção e a promoção do patrimônio histórico e artístico, material e imaterial (inc. II); a valorização e a difusão das criações artísticas e dos bens culturais (inc. III); a universalização do acesso à arte e à cultura (inc. V); e o estímulo à presença da arte e da cultura no ambiente educacional (inc. VI); 
Resta claro, portanto, que a preservação do patrimônio cultural traduz na preservação da própria história do povo, suas tradições e memórias, constituindo a verdadeira identidade que une determinada comunidade por meio de laços que transcendem gerações.

\section{EXPERIÊNCIAS CULTURAIS NO ÂMBITO DAS POLÍTICAS PÚBLICAS DE SAÚDE MENTAL}

3.1 Reforma Psiquiátrica e a transição para o processo de desinstitucionalização

Como salientado, o meio ambiente cultural, formado pelo conjunto de bens, materiais e imateriais, que conferem referência e identidade à memória dos grupos formadores da sociedade, compreende todas as formas de expressão, criações, manifestações artísticoculturais e os espaços a elas destinados, obras e todo e qualquer modo de criar, fazer e viver. Incluem nesse universo as manifestações provenientes de cultura regional, atividades musicais, artes, pintura e toda forma de expressão e criação.

No campo da saúde mental, referidas práticas vêm sendo adotadas como alternativas auxiliares para o tratamento e recuperação de enfermidades desta natureza. Com a reforma psiquiátrica e a tendência da desinstitucionalização, isso ficou mais evidente, em virtude da negação, por parte de alguns setores da sociedade, da eficácia das internações e enclausuramento submetidos aos pacientes até então:

Embora contemporâneo da Reforma Sanitária, o processo de Reforma Psiquiátrica brasileira tem uma história própria, inscrita num contexto internacional de mudanças pela superação da violência asilar. Fundado, ao final dos anos 70, na crise do modelo de assistência centrado no hospital psiquiátrico, por um lado, e na eclosão, por outro, dos esforços dos movimentos sociais pelos direitos dos pacientes psiquiátricos, o processo da Reforma Psiquiátrica brasileira é maior do que a sanção de novas leis e normas e maior do que o conjunto de mudanças nas políticas governamentais e nos serviços de saúde. (BRASIL, 2005b, p. 06)

A reforma psiquiátrica no Brasil começou a ganhar contornos a partir da década de 1970, através de movimentos sociais que passaram a questionar a forma como a assistência psiquiátrica era prestada aos enfermos. Surgiram, nesse período, reivindicações por um serviço mais humanizado, em contraposição ao isolamento asilar utilizado à época. Conforme destacam ANDRADE e MALUF (2017, p. 02) “tal modelo, à época, foi reconhecido como incapaz e ineficiente, nas suas vertentes práticas e teóricas, como mostram os trabalhos de Foucault, Goffman, Cooper, dentre outros”. 
Destacam ainda as autoras que referido movimento, que teve início no contexto do processo de redemocratização do país e de reformulação sanitária, passou a questionar as práticas psiquiátricas adotadas à época, ao tempo em que teceu duras críticas ao tratamento administrado nos hospitais psiquiátricos (ANDRADE; MALUF, 2017, p. 03).

A partir de 1978, o movimento pró reforma psiquiátrica começou efetivamente a surtir efeitos:

O ano de 1978 costuma ser identificado como o de início efetivo do movimento social pelos direitos dos pacientes psiquiátricos em nosso país. O Movimento dos Trabalhadores em Saúde Mental (MTSM), movimento plural formado por trabalhadores integrantes do movimento sanitário, associações de familiares, sindicalistas, membros de associações de profissionais e pessoas com longo histórico de internações psiquiátricas, surge neste ano. É sobretudo este Movimento, através de variados campos de luta, que passa a protagonizar e a construir a partir deste período a denúncia da violência dos manicômios, da mercantilização da loucura, da hegemonia de uma rede privada de assistência e a construir coletivamente uma crítica ao chamado saber psiquiátrico e ao modelo hospitalocêntrico na assistência às pessoas com transtornos mentais. (BRASIL, 2005b, p. 07)

O contexto vivenciado à época, com internações em manicômios e hospitais psiquiátricos, bem como o tratamento dispensado aos doentes, foi determinante para o começo das mudanças então operacionalizadas. Experiências internacionais contribuíram, de forma significativa, para os primeiros passos na construção de um novo modelo. A superioridade dos direitos humanos, fundados na dignidade da pessoa humana, constituiu, de igual maneira, importante marco para a mudança do pensamento coletivo, que passou a enxergar o doente como um sujeito portador de direitos.

Nesse contexto, a cultura antimanicomial começou a se expandir e centros alternativos de tratamento foram sendo criados como formas substitutivas aos hospitais psiquiátricos. Com o novo modelo, a não internação passou a ser prioridade:

Neste período, são de especial importância o surgimento do primeiro CAPS no Brasil, na cidade de São Paulo, em 1987, e o início de um processo de intervenção, em 1989, da Secretaria Municipal de Saúde de Santos (SP) em um hospital psiquiátrico, a Casa de Saúde Anchieta, local de maus-tratos e mortes de pacientes. É esta intervenção, com repercussão nacional, que demonstrou de forma inequívoca a possibilidade de construção de uma rede de cuidados efetivamente substitutiva ao hospital psiquiátrico. Neste período, são implantados no município de Santos Núcleos de Atenção Psicossocial (NAPS) que funcionam 24 horas, são criadas cooperativas, residências para os egressos do hospital e associações. A experiência do município de 
Santos passa a ser um marco no processo de Reforma Psiquiátrica brasileira. Trata-se da primeira demonstração, com grande repercussão, de que a Reforma Psiquiátrica, não sendo apenas uma retórica, era possível e exequível. (BRASIL, 2005b, p. 07)

Em 1989 foi elaborado um projeto de lei - Projeto de Lei deputado Paulo Delgado propondo a regulamentação de direitos de pessoas portadoras de doenças mentais e a extinção progressiva de manicômios no país. Era o início da reforma no campo legal e normativo, que precedeu com a criação do SUS pela CF/88.

Na década de 1990, marcada pela assinatura da Declaração de Caracas e pela realização da II Conferência Nacional de Saúde Mental, surgiram as primeiras normas federais para regulamentar a implantação dos serviços de atenção diária, fundadas nas experiências anteriores dos CAPS, NAPS e Hospitais-dia. No final da década de 1990, funcionavam no Brasil 208 CAPS, mas 93\% dos recursos do Ministério da Saúde utilizados na saúde mental ainda era destinado aos hospitais psiquiátricos (BRASIL, 2005b, p. 08).

Somente em 2001, por meio da Lei n. 10216/2001 (BRASIL, 2001), originária do PL de 1989, foi implementado um novo modelo assistencial em saúde mental. Referido diploma, além de dispor sobre os direitos das pessoas portadoras de transtornos mentais, redirecionou os serviços de saúde prestados nessa área. Dentre as previsões legais, destacam-se medidas que priorizam recursos extra-hospitalares, serviços comunitários e a indicação para internação somente na hipótese de os demais recursos se mostrarem insuficientes (art. $4^{\circ}$ ). Não determinou, porém, a extinção progressiva dos manicômios, como dispunha o projeto original.

Em que pese o diploma normativo não ter adentrado, de forma expressa, na temática da extinção dos hospitais psiquiátricos, instituições substitutivas ao modelo - a exemplo dos Centros de Atenção Psicossocial (CAPS) - foram sendo criadas progressivamente e priorizadas políticas públicas mais inclusivas, contrapostas à internação. Começa-se, então, a perceber uma mudança cultural nesse campo. Nesse sentido:

Linhas específicas de financiamento são criadas pelo Ministério da Saúde para os serviços abertos e substitutivos ao hospital psiquiátrico e novos mecanismos são criados para a fiscalização, gestão e redução programada de leitos psiquiátricos no país. A partir deste ponto, a rede de atenção diária à saúde mental experimenta uma importante expansão, passando a alcançar regiões de grande tradição hospitalar, onde a assistência comunitária em saúde mental era praticamente inexistente. Neste mesmo período, o processo de desinstitucionalização de pessoas longamente internadas é impulsionado, com a criação do Programa "De Volta para Casa”. Uma política de recursos humanos para a Reforma Psiquiátrica é construída, e é traçada a política para a 
questão do álcool e de outras drogas, incorporando a estratégia de redução de danos. Realiza-se, em 2004, o primeiro Congresso Brasileiro de Centros de Atenção Psicossocial, em São Paulo, reunindo dois mil trabalhadores e usuários de CAPS. (BRASIL, 2005b, p. 09)

A partir desse cenário, passa-se, então, a verificar a efetiva transição do modelo de assistência à saúde mental centrada em hospitais psiquiátricos para um modelo voltado à atenção comunitária, à fiscalização e à redução progressiva e programada dos leitos psiquiátricos existentes. Consolida-se, portanto, a Reforma Psiquiátrica como política oficial do governo (BRASIL, 2005b, p. 09).

A partir da mudança de paradigma, é possível notar nas políticas públicas de saúde mental a priorização da integração social e cultural dos pacientes, mediante acompanhamento terapêutico multiprofissional, com a inserção dos familiares nesse dinâmico processo. Tais programas são desenvolvidos, em sua grande maioria, nos Centros de Atenção Psicossocial CAPS instalados em diversos municípios brasileiros.

Os CAPS são instituições destinadas a acolher os pacientes com transtornos mentais, estimular sua integração social e familiar, apoiálos em suas iniciativas de busca da autonomia, oferecer-lhes atendimento médico e psicológico. Sua característica principal é buscar integrá-los a um ambiente social e cultural concreto, designado como seu território, o espaço da cidade onde se desenvolve a vida quotidiana de usuário (BRASIL, 20--?, texto sem numeração)

Os CAPS estão em funcionamento em todo o país e, para fins de melhor prestação dos serviços, são divididos em categorias, conforme a densidade populacional. Referidos centros contribuíram sobremaneira com a ampliação da política de desinstitucionalização no país, na medida em que passaram a prestar a assistência à saúde mental mediante serviços substitutivos à internação hospitalar, constituindo verdadeira rede extra-hospitalar no tratamento do ramo, mediante o desenvolvimento de atividades que favorecem a inclusão social e cultural.

Além dos serviços prestados nos CAPS, foram instituídos outros programas que priorizam a não internação e que desenvolvem o tratamento por meio de políticas que garantem uma maior autonomia aos pacientes:

O Programa Nacional de Avaliação do Sistema Hospitalar/Psiquiatria (PNASH/Psiquiatria), o Programa Anual de Reestruturação da Assistência Hospitalar Psiquiátrica no SUS (PRH), assim como a instituição do Programa de Volta para Casa e a expansão de serviços como os Centros de Atenção Psicossocial e as Residências Terapêuticas, vem permitindo a redução de milhares de leitos psiquiátricos no país e o fechamento de vários hospitais psiquiátricos. 
Embora em ritmos diferenciados, a redução do número de leitos psiquiátricos vem se efetivando em todos os estados brasileiros, sendo muitas vezes este processo o desencadeador do processo de Reforma. (BRASIL, 2005b, p. 13-14)

Nos CAPS são desenvolvidos diversos tipos de atividades com o fim de promover a reinserção social dos pacientes. São priorizadas atividades culturais, como parte do processo terapêutico, o que vem a corroborar a influência que o meio ambiente cultural exerce sobre a saúde humana, em especial a saúde mental. Nesse sentido:

Os CAPS devem ser substitutivos, e não complementares ao hospital psiquiátrico. Cabe aos CAPS o acolhimento e a atenção às pessoas com transtornos mentais graves e persistentes, procurando preservar e fortalecer os laços sociais do usuário em seu território. De fato, o CAPS é o núcleo de uma nova clínica, produtora de autonomia, que convida o usuário à responsabilização e ao protagonismo em toda a trajetória do seu tratamento. (BRASIL, 2005b, p. 27)

Ao lado dos CAPS, os Centros de Convivência e Cultura, instalados em alguns municípios brasileiros, surgem como meios fortalecedores do atual modelo na atenção à saúde mental, conforme se vê:

Os Centros de Convivência e Cultura são dispositivos públicos que compõe a rede de atenção substitutiva em saúde mental e que oferecem às pessoas com transtornos mentais espaços de sociabilidade, produção cultural e intervenção na cidade. Estes Centros, através da construção de espaços de convívio e sustentação das diferenças na comunidade, facilitam a construção de laços sociais e a inclusão das pessoas com transtornos mentais. O valor estratégico e a vocação destes Centros para efetivar a inclusão social residem no fato de serem equipamentos concebidos fundamentalmente no campo da cultura, e não exclusivamente no campo da saúde. Os Centros de Convivência e Cultura não são, portanto, equipamentos assistenciais e tampouco realizam atendimento médico ou terapêutico. São dispositivos públicos que se oferecem para a pessoa com transtornos mentais e para o seu território como espaços de articulação com a vida cotidiana e a cultura. (BRASIL, 2005b, p. 38)

Os centros de convivência e cultura, portanto, visam a restaurar a sociabilidade da pessoa portadora de transtornos mentais e promover o desenvolvimento do paciente através de práticas culturais que contribuirão, ainda que reflexamente, com a melhoria da saúde mental do indivíduo.

Atualmente, referidas práticas são postas à sociedade como meios autônomos no processo terapêutico dos transtornos mentais e, aliadas a tantas outras políticas públicas com a 
mesma finalidade, constituem um novo método no processo de cura, no auxílio à redução do estigma sofrido por esses pacientes e na ampliação da autoestima. Pelas experiências vistas, esse novo método tem trazido significativos avanços para a terapêutica em saúde mental e contribuído sobremaneira para a materialização de um tratamento humanizado e condizente com a qualificação de pessoa humana. Embora muito ainda possa ser feito, a adoção do modelo constitui um avanço na definição das políticas públicas sociais.

3.2 Práticas culturais utilizadas como parte do processo terapêutico na assistência à saúde mental

O meio ambiente cultural, especialmente no que toca aos bens imateriais, como as manifestações artísticas e culturais, formas de expressão, modos de criar, fazer e viver, vem sendo um importante aliado no processo terapêutico de assistência à saúde mental. Os espaços públicos destinados às manifestações culturais, tais como cinemas, teatros, museus, bibliotecas, também têm contribuído para a promoção do bem-estar dos pacientes portadores de transtornos mentais.

Políticas públicas que buscam reinserir o paciente na sociedade, através da promoção de práticas culturais, têm se tornado cada vez mais frequentes. Esse processo teve início, ainda que muito timidamente, com o processo inicial da reforma psiquiátrica. Nos dias atuais, contudo, isso tem se tornado cada vez mais comum. Referidas práticas, para além da promoção de melhoria no bem-estar dos portadores de transtornos mentais, contribuem para minorar as consequências que o estigma e a exclusão social acarretam na vida desses pacientes e funcionam como modos autênticos de transformação social:

Diversos grupos culturais vêm se constituindo no campo da reforma, com atividades como teatro, música, artes plásticas, rádio comunitária, TV experimental, folclore, literatura. Já existe uma significativa produção nesta área. Do mesmo modo, grupos culturais já estabelecidos têm sido chamados a contribuir com o debate da reforma, especialmente enfocando os desafios do modelo assistencial e o combate ao estigma. Exemplo disto é o Teatro do Oprimido, fundado e dirigido por Augusto Boal, que participa de atividades de CAPS e outras iniciativas em diversos estados do país. (BRASIL, 2005b, p. 46)

Atividades artístico-culturais, das mais variadas, estão sendo inseridas no contexto do tratamento psiquiátrico como meios autônomos e independentes para auxiliar o processo de cura. Não se trata da adoção de meios secundários e/ou acessórios, mas de meios independentes, que integram o contexto do tratamento de forma singular, enquanto parte dele. AMARANTE e 
TORRE (2017, p. 2) destacam que este fato faz com que a Reforma Psiquiátrica seja vista como um movimento social que rompe barreiras, na medida em que passa a enxergar o portador de doença mental como um sujeito capaz de trocas sociais, de convivência em liberdade e de produzir algo válido do ponto de vista social ou econômico.

Práticas alternativas baseadas em arte e cultura têm se demonstrado paradigmáticas na evolução da terapêutica de saúde mental e, bem por isso, traduzem modos efetivos de reinserção social do portador de transtornos dessa natureza. Complementam os autores:

As experiências de arte-cultura estariam produzindo rupturas em relação a pontos fundamentais do paradigma psiquiátrico, ampliando os espaços de cidadania e circulação social dos sujeitos em sofrimento mental ou situação de vulnerabilidade psicossocial. Tais rupturas dizem respeito ao deslocamento da ideia de doença mental como incapacidade e inferioridade; à crítica do discurso científico e técnico como lugar da verdade; à crítica da ideia de cultura como restrita à arte institucionalizada; e à crítica da noção de arte e cultura como terapêutica. Essas rupturas se relacionam ainda com uma redefinição de conceitos, com a ampliação e transformação do conceito de cultura e da noção de reforma psiquiátrica. (AMARANTE; TORRE, 2017, p. 2)

Referidas experiências, portanto, vêm contribuindo significativamente para uma nova perspectiva no âmbito da saúde mental. As manifestações culturais e as formas de expressão, de criar, fazer e viver, enquanto inseridas no contexto do meio ambiente cultural - bem essencial à sadia qualidade de vida de toda a coletividade - são visualizadas como modalidades terapêuticas no campo da saúde mental, na medida em que restauram (ou, ao menos, auxiliam a restaurar) a cidadania do portador desse tipo de patologia. Ainda, reinserem-no ao seio social, promovem o melhor diálogo com os demais atores sociais envolvidos nesse processo e, consequentemente, contribuem para a evolução do quadro físico-psíquico do paciente. Explicitam AMARANTE e TORRE (2017, p. 2):

Por sua vez, para uma ressignificação do conceito de cultura, existem duas abordagens importantes: primeiro, a discussão sobre a arte-cultura como linguagem dialógica que supera e transcende a racionalidade científica (rompendo com o discurso técnico e especialístico e com as relações de poder advindas do modelo biomedicalizante). A partir daí, a cultura deixa de ser restrita à arte institucionalizada ou a formalismos escolásticos para ser instrumento na construção de identidades coletivas e direitos de cidadania, funcionando como "resistência ao poder", questionando a noção de cultura dita nobre em superioridade à cultura popular e, portanto, rompendo com o discurso dominante no campo da arte e cultura. 
Atividades culturais desenvolvidas com o objetivo de auxiliar a terapêutica na área de saúde mental têm funcionado como importantes mecanismos para uma maior aproximação da sociedade com os portadores de transtornos mentais, diminuindo, assim, o abismo até então propalado e que tanto contribuiu para o alijamento dos doentes. Além disso, referidas atividades fortalecem o aspecto criativo dos pacientes, amplia os laços com os familiares e com a sociedade, estimula o desenvolvimento de novas habilidades e melhora a autoestima.

Compete ressaltar que o tratamento medicamentoso, puro e simples, não alcança a necessária eficácia que esse tipo de patologia parece reclamar. Os estudos sugerem que a inserção de práticas culturais no tratamento, conjuntamente com a esfera medicamentosa, promove melhoras significativamente superiores, na medida em que restaura o bem-estar íntimo do paciente, enquanto ser independente, dotado de autonomia.

Sendo assim, o trabalho sociocultural no processo terapêutico é fundamental para alcançar a proximidade, tanto quanto possível, da cura. Ademais, constitui importante fator para melhoria das relações sociais:

$\mathrm{Na}$ dimensão sociocultural ocorrem importantes estratégias e dispositivos para a transformação do lugar social da loucura, ou, dito de outra forma, de transformação das relações entre a sociedade e a loucura. Considerando a quantidade, a qualidade, o impacto e a expressão cultural que esses diversos projetos artístico-culturais recentemente constituídos estão produzindo, é possível dizer que se está assistindo à constituição de um movimento social cultural como base desse novo campo artístico-cultural. (AMARANTE et al, 2012, p. 2)

As manifestações artístico-culturais, portanto, traduzem um novo modelo de compreensão sobre a saúde mental no país, na medida em que aproximam o portador de transtorno mental da vida participativa em sociedade. Em consequência, contribuem para a evolução da cura e ampliam o bem-estar do paciente. Desse modo, o meio ambiente cultural emerge como importante ferramenta nesse processo.

Vale destacar que em muitos CAPS são realizadas oficinas de arte e cultura, com vistas a promover uma melhor integração do doente com a sociedade em que vive. É o que ocorre, por exemplo, na Universidade Federal do Ceará, através do projeto “Arte como recurso terapêutico em pacientes com transtornos mentais”:

O projeto "A arte como recurso terapêutico em pacientes com transtornos mentais" mantido pelos acadêmicos de medicina da Universidade Federal do Ceará nos centros de Atenção Psicossociais de Barbalha e Juazeiro do Norte, visam ao desenvolvimento de conhecimentos, habilidades e atitudes dos pacientes psiquiátricos 
dentro de suas limitações. Além disso, criam condições para que os pacientes com transtornos mentais possam inserir-se plenamente na sociedade. Também realizam atividades lúdicas visando, não somente o lazer, mas principalmente buscando desenvolver ações educativas e incentivando a abertura e realização de novas ações na área de saúde mental.

Assim, como forma de avaliar o trabalho de extensão dos acadêmicos de medicina da Universidade Federal do Ceará, procurou-se conhecer até que ponto, estimular atividades artísticas para os pacientes psiquiátricos, em forma de tratamento complementar, ajudaria a desenvolver conhecimentos, habilidades e atitudes, dentro de suas limitações, facilitando sua inserção social. (OLIVEIRA; MALVEIRA; MOREIRA, 2012, texto sem numeração)

Pode-se perceber, portanto, que a inserção de práticas culturais como parte integrante da terapêutica de saúde mental aparece como um novo marco para a definição das políticas públicas de saúde mental no Brasil, pois, além de favorecer o próprio processo de cura, favorece a sociabilidade do portador de transtornos mentais, amplia o processo criativo e faz com que a sociedade passe a enxergar os portadores de transtornos mentais de forma mais humanizada e menos excludente.

O meio ambiente cultural participa, portanto, desse contexto, uma vez que as atividades desenvolvidas com vistas a propiciar essa forma de tratamento são decorrentes dos bens - materiais e imateriais - que integram esse ramo do meio ambiente. Mostra-se, pois, de salutar importância a sua preservação para a sadia qualidade de vida dos indivíduos que a integram. E, mais que isso, mostra-se quão relevante a preservação e conservação do patrimônio cultural brasileiro são para a reabilitação da saúde mental do indivíduo acometido por transtornos mentais.

A cultura, por essência, é fundamental à formação da identidade de um povo, pois através dela identifica-se a história, a memória e a cidadania dos indivíduos que compõem a sociedade. Adicionalmente a isso, vem se mostrando importante aliada terapêutica no processo de cura dos problemas decorrentes da saúde mental, fato que contribui para a necessidade de sua maior proteção e fomento.

Também, através da cultura, se estreitam as relações sociais e os modos de diálogo entre os integrantes de dada sociedade. Bem por isso, é de suma importância que a "loucura” encontre espaço de expressão no seio cultural, de modo a ser socializada, ser vista e aceita em sua complexidade e, dessa forma, ser destinatária de novas políticas públicas sociais (AMARANTE et al, 2012). 
Cumpre, assim, ressaltar que referidas práticas têm sido adotadas com certa autonomia nas políticas públicas de saúde mental, de modo auxiliar ao tratamento medicamentoso, e os resultados têm se mostrado essencialmente positivos - positivos enquanto fatores de redução de exclusão social, enquanto modos de aquisição de uma maior sociabilidade do paciente e enquanto formas de ampliação da cidadania e autoestima.

\section{CONCLUSÃO}

Diante do que foi tratado no presente ensaio, podemos concluir que o meio ambiente cultural possui fundamental papel no cenário das políticas públicas de saúde mental adotadas no Brasil.

Foi demonstrado que, a partir da reforma psiquiátrica, por meio de ações que priorizam a não internação, passaram a ser inseridas no curso do tratamento dos transtornos psiquiátricos atividades de natureza artístico-culturais como formas autônomas de terapias alternativas. Referidas atividades, para além do benefício causado ao próprio portador, auxiliam na transformação social, na medida em que reinserem o paciente ao contexto em que vive, conferem-lhe autonomia e melhoram sua autoestima. Embora ainda distantes do ideal, é indubitável que a adoção desse modelo, quando da definição das políticas públicas, constitui um importante passo para uma melhor concreção de direitos e maior aplicabilidade de uma justiça social.

A par desses benefícios, restou demonstrado que práticas culturais contribuem para a redução do estigma sofrido pelos pacientes portadores de transtornos mentais e melhoram significativamente a qualidade de vida desses sujeitos, na medida em que lhes dotam de autonomia perante os demais. As manifestações culturais, das mais variadas formas, enquanto partes integrantes do patrimônio cultural brasileiro, constituem formas autênticas de promoção de sociabilidade e, especificamente no âmbito da saúde mental, têm trazido significativos benefícios.

Afora esses e tantos outros fatores, percebe-se que a preservação do meio ambiente cultural mostra-se imprescindível à sadia qualidade de vida dos indivíduos, à adequada promoção da saúde, à ampliação da cidadania e ao fortalecimento dos laços sociais que unem os integrantes de dada sociedade. 


\section{REFERÊNCIAS}

ALVAREnGA, Rúbia Zanotelli. Princípios fundamentais de Direito Ambiental do Trabalho. Revista Fórum Trabalhista. Belo Horizonte, ano 3, n. 12, maio/jun. 2014.

AMARANTE, Paulo et al. Da diversidade da loucura à identidade da cultura: o movimento social cultural no campo da reforma psiquiátrica. Caderno Brasileiro de Saúde Mental. Rio de Janeiro, v. 4, n. 8, p. 125-132, jan./jun. 2012.

AMARANTE, Paulo; TORRE, Eduardo Henrique Guimarães. Loucura e diversidade cultural: inovação e ruptura nas experiências de arte e cultura da Reforma Psiquiátrica e do campo da Saúde Mental no Brasil. Revista Interface (Botucatu) [online]. 2017, vol.21, n.63, pp.763774.

ANDRADE, Ana Paula Müller de; MALUF, Sônia Weidner. Experiências de desinstitucionalização na reforma psiquiátrica brasileira: uma abordagem de gênero. Revista Interface (Botucatu) [online]. 2017, vol.21, n.63, pp.811-821.

ANTUNES, Paulo de Bessa. A tutela judicial do meio ambiente. Rio de Janeiro: Lumen Juris, 2009.

BRASIL. 284 mais sobre os serviços disponíveis em saúde mental. Disponível em: $<$ http://portalsaude.saude.gov.br/index.php/cidadao/acoes-e-programas/conte-com-agente/leia-mais-conte-com-a-agente/284-mais-sobre-os-servicos-disponiveis-em-saudemental>. 20--?. Acesso em: 12 de dezembro de 2017.

BRASIL. Constituição da República Federativa do Brasil de 1988, de 05 de outubro de $1988 . \quad$ Disponível em: <http://www.planalto.gov.br/ccivil_03/constituicao/constituicaocompilado.htm>. Acesso em: 12 dez. 2017.

BRASIL. Decreto-Lei $\mathbf{n}^{\mathbf{0}}$. 25, de 30 de novembro de 1937. Disponível em: <http://www.planalto.gov.br/ccivil_03/decreto-lei/Del0025.htm>. Acesso em: 12 dez. 2017.

BRASIL. Emenda Constitucional $\mathbf{n}^{\mathbf{0}}$. 48, de 10 de agosto de 2005a. Disponível em: $<$ http://www.planalto.gov.br/ccivil_03/constituicao/emendas/emc/emc48.htm>. Acesso em 18 jan. 2018.

BRASIL. Lei $\mathbf{n}^{\mathbf{0}}$. 10.216, de 06 de abril de 2001. Disponível em: $<$ http://www.planalto.gov.br/ccivil_03/leis/leis_2001/l10216.htm>. Acesso em: 12 de dezembro de 2017.

BRASIL. Lei $\mathbf{n}^{\mathbf{0}}$. 12.343/2010, de 02 de dezembro de 2010. Disponível em: $<$ http://www.planalto.gov.br/ccivil_03/_ato2007-2010/2010/lei/l12343.htm>. Acesso em: 12 dez. 2017.

BRASIL. Ministério da Saúde. Secretaria de Atenção à Saúde. DAPE. Coordenação Geral de Saúde Mental. Reforma psiquiátrica e política de saúde mental no Brasil. Documento apresentado à Conferência Regional de Reforma dos Serviços de Saúde Mental: 15 anos depois de Caracas. OPAS. Brasília, novembro de 2005b. 
CARDOSO, Simone Tassinari. O direito ao lazer no estado socioambiental. Tese de Doutorado. Porto Alegre: Pontifícia Universidade Católica do Rio Grande do Sul, 2011. Disponível em: <http://repositorio.pucrs.br/dspace/handle/10923/2324> . Acesso em 18 mar. 2018.

FELICIANO, Guilherme Guimarães. Reconhecendo a danosidade sistêmica. In: FELICIANO, Guilherme Guimarães; URIAS, João (Coord.). Direito ambiental do trabalho: apontamentos para uma teoria geral. São Paulo: LTr, 2013. v. 1.

MIRANDA, Marcos Paulo de Souza. Patrimônio Ambiental Cultural: usucapião de bens móveis tombados - uma análise em busca da efetividade protetiva do Dec.-Lei 25/37. Revista de Direito Ambiental. São Paulo: Revista dos Tribunais, v.41, p. 167-181, jan.-mar. 2006.

OLIVEIRA, Gislente; MALVEIRA, Plínio; MOREIRA, Josefa. Arteterapia e Saúde Emocional de Pacientes em Tratamento no CAPS. 2012. Disponível em: $<$ https://psicologado.com/psicopatologia/saude-mental/ arteterapia-e-saude-emocional-depacientes-em-tratamento-no-caps > . Acesso em: 14 de dezembro de 2017. 